Abstract AB1168 - Table 1. Clinical \& US examination details on knees \& ankles of 10 children (40 joints)

\begin{tabular}{|c|c|c|c|c|c|c|c|c|c|}
\hline Patients & Diagnosis & $\begin{array}{l}\text { Rt Knee } \\
\text { Clinical }\end{array}$ & $\begin{array}{c}\text { Rt Knee } \\
\text { US }\end{array}$ & $\begin{array}{l}\text { Lt Knee } \\
\text { Clinical }\end{array}$ & $\begin{array}{c}\text { Lt Knee } \\
\text { US }\end{array}$ & $\begin{array}{c}\text { Rt Ankle } \\
\text { Clinical }\end{array}$ & $\begin{array}{c}\text { Rt Ankle } \\
\text { US }\end{array}$ & $\begin{array}{c}\text { Lt Ankle } \\
\text { Clinical }\end{array}$ & Lt Ankle US \\
\hline$\overline{P t} 1$ & SJIA & + & + & + & + & - & + & + & + \\
\hline Pt 2 & SJIA & - & - & - & - & + & + & - & - \\
\hline Pt 3 & ERA & - & - & - & - & - & - & + & $\begin{array}{c}- \\
\text { TP } \\
\text { tenosynovitis }\end{array}$ \\
\hline Pt 4 & ERA & - & - & - & - & - & - & + & $\begin{array}{c}- \\
\text { TA } \\
\text { tenosynovitis }\end{array}$ \\
\hline Pt 5 & PJIA & - & - & - & - & - & + & - & - \\
\hline Pt 6 & PJIA & + & + & + & + & - & - & - & - \\
\hline Pt 7 & ERA & + & + & - & - & + & EDL TS + & - & - \\
\hline Pt 8 & ERA & - & - & - & - & + & - & - & - \\
\hline Pt 9 & PJIA & + & + & + & + & - & - & + & + \\
\hline Pt 10 & PJIA & + & + & + & - & + & - & - & - \\
\hline
\end{tabular}

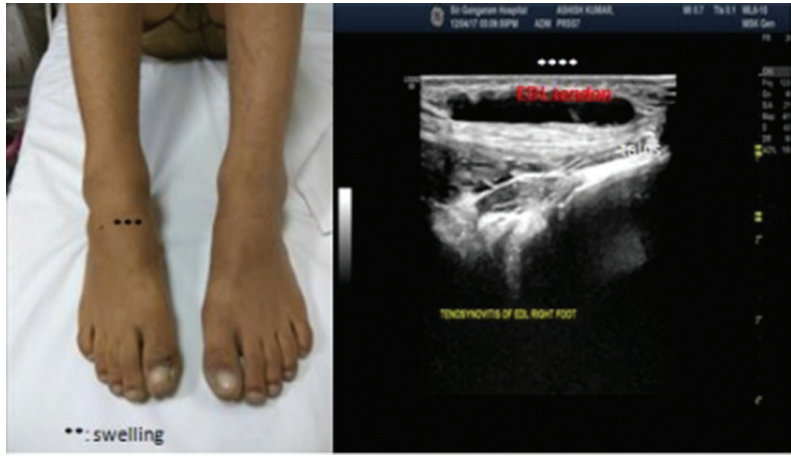

Abstract AB1168 - Figure 1

Conclusions: With gold standard as US for detection of synovitis, sensitivity of clinical examination-100\% for knee, specificity-91.7\%. For clinical examination of ankles, sensitivity-60\% and specificity- $66.7 \%$ suggesting possibility of mistaking an adjacent tendon sheath swelling for a TT joint disease. This has important implications for systemic therapies and intervention. The US is a valuable addition to clinical examination of the joints. Clinical examination alone in this pilot study of 10 children with JIA is inadequate to assess disease of the ankles. Evidence shows US to be superior to the clinical examination alone, but the lack of validated US findings, scoring systems and treatment algorithms exposes the need for further research.

Disclosure of Interest: None declared

DOI: 10.1136/annrheumdis-2018-eular.5254

\section{AB1169 CAN ULTRASOUND-DETECTED SYNOVITIS PREDICT RADIONUCLIDE SYNOVECTOMY EFFICACY IN CHRONIC INFLAMMATORY RHEUMATISM?}

A.S. Amouzougan ${ }^{1}$, H. Marotte ${ }^{2}$, K. Boussoualim ${ }^{1}$, L. Mijola ${ }^{1}$, P. Collet ${ }^{1}$, B. PallotPrades $^{1}$, N. Prévot-Bitot ${ }^{3}$, F.-G. Barral ${ }^{4}$, T. Thomas ${ }^{2} .{ }^{1}$ Rheumatology, Universital Hospital of Saint-Etienne; ${ }^{2}$ Rheumatology, Inserm 1059, Universital Hospital of Saint-Etienne; ${ }^{3}$ Nuclear Medecine; ${ }^{4}$ Radiology, Universital Hospital of SaintEtienne, Saint-Etienne, France

Background: The better management of inflammatory joint diseases, including biological treatments, has not eliminated in the clinical practice the persistence of chronic inflammatory monoarthritis despite local glucocorticosteroids (GC) injection and optimal systemic treatment. No therapeutic consensus was proposed in this clinical situation. In addition, radionuclide synovectomy (RS) was proposed with no clear benefit-risk effect. However, it has been shown that ultrasounddetected residual synovitis is frequent and predictable to relapse and structural progression in rheumatoid arthritis patients.

Objectives: We explored ultrasound-detected synovitis predictive value of response to RS in chronic inflammatory monoarthritis.

Methods: A monocentric prospective study was performed including unclassified monoartrhitis, rheumatoid arthritis, spondyloarthritis, and lupus between January 2012 and December 2017. All patients already received GC intra-articular injections $(\mathrm{GCl})$ and were treated in particular by cs or bDMARDS. On the day of the $\mathrm{RS}$ performed by a radiologist under radioscopic control, all patients had an articular power Doppler $(\mathrm{PD} ; 0-3)$ with greyscale $(\mathrm{GS} ; 0-3)$ ultrasonography with a MyLab 60 - EASAOTE, by 2 experimented sonographers.
Primary endpoint (EP) was subjective overall improvement $>50 \%$ without of any $\mathrm{GCl}$ and/or surgical management at 6 months (M).

Chi-square test was used to check the difference between groups.

Results: Data from 23 patients, 17 women and 6 men, with mean age $54 \pm 14$ years were analysed. Eleven RA $(45.5 \% R F$ +or $A C P A+), 3$ pSpA, 2 axSpA HLA B27+, 1 Lupus, and 6 unclassified monoartrhitis ( $F R$ and $A C P A-)$. Histological analysis of the synovium in 7 patients concluded to chronic nonspecific synovitis. Twenty eight joints were treated. Of them, 25 were coted US GS $>2$ and/or DP $\geq 2$. None had US $G S=0$ and $D P=0$. Effusion on US exam was reported in 24 joints.

On X-ray, $46.4 \%$ of patients had joint space narrowing and/or erosion. ESR or CRP increased in $43.5 \%$. Forty five previous $\mathrm{GCl}$ were declared (Cortivazol or triamcinolone hexacetonide), with a median at $2 .^{1-6}$

Patients were treated with methotrexate, $n=16$ (69.6\%), hydroxychloroquine, $n=1$, bDMARDS, $n=11$ (48\%), oral GC, $n=8(35 \%)$ and non-steroidal anti-inflammatory drug, $\mathrm{n}=6(26 \%)$.

At $\mathrm{M} 6$ and $\mathrm{M} 12,64.6 \%$ of patients reached the EP. One patient reached the EP only at M12 and another one only at M6. No significant differences were observed between groups in terms of PDUS (DP $\geq 2$ vs $D P \leq 1$ ), unclassified monoartrhitis, and joint space narrowing and/or erosion.

Only one patient had pain exacerbation 24 hour after RS followed by a quick recovery.

Conclusions: In chronic inflammatory monoarthritis, PDUS was not predictive of clinical outcome after RS. However, this intra-articular procedure appeared effective in either unclassified or classified monoarthritis or in presence of radiographic joint lesions.

Disclosure of Interest: None declared

DOI: 10.1136/annrheumdis-2018-eular.6850

\section{AB1170 1 FIRST RESULTS OF THE RHEUMATOID ARTHRITIS HANDSCAN REGISTRY LEEUWARDEN}

A. Al Hasan, R. Bos, N. Veeger, D. Zhang, L. Hendriks, F. Wink, A. Schilder, F. Reimann, K. Bergsma. MEDISCH CENTRUM LEEUWARDEN, Leeuwarden, Netherlands

Background: The handscan is a new technologic device which uses diffuse optical transmission in combination with blood flow modulation. It is a non-invasive measurement of joint inflammation potentially more sensitive than the clinical evaluation of the joints by a rheumatologist[. ${ }^{1}$ However, more clinical data is necessary before this new device can be implemented in the daily clinical practice. Objectives: This study investigates the additional value of the handscan in decision making in the daily practice for patients with rheumatoid arthritis.

Methods: At our outpatient clinic we started a registry for rheumatoid arthritis patients with a disease duration of at least two years. During this period, a hands can will be made for all patients before every regular visit. Both the patient and the treating rheumatologist will be blinded to the handscan outcome. Primary outcome is the association between DAS28 score and the total optical score (TOS) of the handscan per visit.

Results: The study started in December 2017, until now 100 patients are included. The mean age was 61.1 years, the mean disease duration at time of inclusion 11.2 years, $67 \%$ were rheumatoid factor positive, $51 \%$ were anti-CCP positive. In figure 1 we show the association between DAS28 and the TOS in a lin ear model.

Currently there is no validated cut off point for the TOS (negative or positive score for inflammation). In our group of 100 patients the median TOS was 10 , the most discriminating TOS was found to be 17 using chi-square test as depicted in table 1. 